\title{
Twinkle Twinkle Little Star How Subjective Norm Mediates So Far? Formation Of Social Entrepreneurship Intention In Malaysia
}

\author{
Siti Daleela Mohd Wahid, Abu Hanifah Ayob, Wan Mohd Hirwani Wan Hussain
}

\begin{abstract}
Social entrepreneurship is a global phenomenon spreading around the world. It has become one of the finest solutions for addressing various social, environmental and economic issues. Following the issue of unemployment among graduates, research involving how far students are willing to become a social entrepreneur is relevant to be conducted. With that, this paper aims at revealing factor that predict a student's intention to be social entrepreneurs in the future. This study is quantitative in nature and has employed cross-sectional approach. Drawing from the theory of reasoned action as a theoretical foundation, this paper identifies trait emotional intelligence as the exogenous and subjective norm as the mediator. Stratified sampling strategies involves 480 undergraduate students from public and private universities were selected as respondents, at the same time as information become amassed via surveys. The information become then analyzed via the use of AMOS software. The structural equation modelling (SEM) was executed to test hypotheses. The results exhibit that subjective norm is partially mediates the tested relationship. This research contributes to shed light on the literature via examining a comprehensive models of social entrepreneurship intention formation; whilst offering several important practical implications for social entrepreneurship educators and practitioners.
\end{abstract}

Index Terms: Social entrepreneurship intention, trait emotional intelligence, subjective norm, theory of reasoned action

\section{INTRODUCTION}

Social Entrepreneurship (SE) is an innovative entrepreneurial approach that helps in eradicating the socioeconomic problems faced by many countries of the world. Currently, this innovative approach has received a great call and growing concern from local and global parties (policies makers, academicians, practitioners) because of its considerable effect at the social and economic transformation of a country (Wahid, Ayob, \& Wan Hussain, 2018a; Ayob, 2017; Barton, Schaefer, \& Canavati, 2018). Among the important roles of SE to a society are its ability in eliminating extreme poverty, getting basic education universally, championing gender equality while at the same time empowering women, reducing child mortality, as well

Revised Manuscript Received on April 19, 2019.

Siti Daleela Mohd Wahid, Faculty of Business Management, Universiti Teknologi MARA, Melaka Branch, Alor Gajah, Melaka, Malaysia.

Abu Hanifah Ayob, Faculty of Economics and Management, The National University of Malaysia, Bangi, Selangor, Malaysia.

Wan Mohd Hirwani Wan Hussain, Graduate School of Business, The National University of Malaysia, Bangi, Selangor, Malaysia. as preserving nature and the environment (Ab Wahid, Wan Mustaffa, Mohd Rhouse, \& Abdul Rahman, 2016).

In Malaysia, the agenda of inclusivity has always been the central tenet of the government where the marginalized group is put as one of the top priorities. This has been one of the steps adopted towards becoming a developed nation by 2020. Despite living harmoniously within different ethnicities, socioeconomic problem remains a constant occurrence. Although the international poverty lines are gradually decreasing, 6 per cent of Malaysian households are still earning less than RM1,141 per month; representing about 1.9 million of Malaysian total population. This signifies that a portion of Malaysians are being deprived of necessities of life, such as good living standard, education, which are results of unemployment and illiteracy (Wahid, Ayob, \& Wan Hussain, 2018b).

In lieu of this, social entrepreneurship programs can be used to eradicate these problems through the placement of those less privileged towards a better life (Tran, 2017). However, the prevalence rate of SE activity in Malaysia is just 2 per cent, which is far behind other developing countries such as Thailand and Indonesia (Wahid, Wan Hussain, \& Ayob, 2018a). The report in Global Entrepreneurship Monitor 2015 mentioned that the number of Malaysians who are active social entrepreneurs is one of the lowest as compared to other developing economies. The low SE figure indicates a "hassle" for the Malaysian society because the country may be lacking out to innovatively support its citizens (Wan Hussain, Ab Rahman, Zainol, \& Yaakub, 2014).

Having realised that SE in Malaysia is acceptable, and the current level could be very low, an urgent question arises; how can the level of SE in Malaysia be increased? Preceding studies via (Tiwari, Bhat, \& Tikoria, 2018) advised that, entrepreneurship can simplest be multiplied if the general schedule of entrepreneurship is fostered. In ensuring that individuals become social entrepreneurs, the antecedents influencing their intentions need to be studied. Past literature has listed numerous factors that influence intentions, such as in moral obligation (Hockerts, 2017), empathy (Ayob, Yap, Amat Sapuan, \& Abdul Rashid, 2013), creativity (Kedmenec, Rebernik, \& Perip, 2015), 
self-efficacy (Tran \& von Korflesch, 2016).

Nevertheless, they tend to ignore the importance of emotional intelligence (EI) which affects an individual's intention (Tiwari, Bhat, \& Tikoria, 2018; Tiwari , Bhat, \& Tikoria, 2017). In fact, emotional factors are the major cause for business failure (Walsh \& Cunningham, 2016; Shepherd, Patzelt, \& Wolfe, 2012; Shepherd, Wiklund, \& Haynie, 2009) Although the relationship between EI and SE Intention has been tested in the past (Tiwari, Bhat, \& Tikoria, 2018; Hassan \& Omar, 2016; Zampetakis, Kafetsios, Bouranta, Dewett, \& Moustakis, 2009) yet, an inconclusive result leads to further investigations is still needed (Creswell, 2014). Therefore, this current research advances the studies of (Tiwari, Bhat, \& Tikoria, 2018; Hassan \& Omar, 2016; Zampetakis, Kafetsios, Bouranta, Dewett, \& Moustakis, 2009) from both theoretical and methodological aspects. First, those studies examined EI as a single explanatory variable; whilst this research has separated examination for EI. Hence, the model is modified following specifically the context of SE as opposed to the conventional entrepreneurship. Second, the survey of those studies by (Hassan \& Omar, 2016) (Tiwari, Bhat, \& Tikoria, 2018) were distributed to students in premier private universities. Meanwhile, (Zampetakis, Kafetsios, Bouranta, Dewett, \& Moustakis, 2009) underwent a survey for business, engineering and business students in public universities. To advance, our research data were collected from students of various majors in both public and private HLIs. Lastly, the findings in those studies were inconclusive, which have led us to offer a refinement in the context of SE (Creswell, 2014).

\section{LITERATURE REVIEW}

\section{A. Theory of Reasoned Action}

The theory of reasoned action (TRA) was established and turn evolved by Fishbein \& Ajzen (1975) addresses the effects of cognitive components, such as subjective norms and intentions on behaviors. In other words, TRA describes how human beings make analytical decisions and consider the consequences before they decide to act or not. On the other hand, behavioral intentions are the most effective single predictor of a person's behavior (Krueger, Reilly, \& Carsrud, 2000). Fishbein \& Ajzen (1975) explain the TRA is different in two conceptually beliefs-behavioral and normative. Behavioral is referring to the individual's perception toward behavior. Normative is an individual's perception of other's thinking on the behavior performed.

Utilizing TRA as the foundation, TRA posit trait EI capable to function as salient beliefs that acting a behavior; can result in a selected outcome Fishbein \& Ajzen (1975). In addition, Altawallbeh, Soon, Thiam, \& alshourah (2015) stated subjective norm successfully act as the mediator to solve any inconclusive findings between salient belief and outcomes (i.e., SE intention). Therefore, TRA is relevant as the theoretical background of the study which aiming to understand how student's norm response on the association between trait EI and SE intention.

B. The Concept of Social Entrepreneurship, Social Entrepreneur and Social Enterprise
The idea of entrepreneurship was first existed and described more than 250 years in the past, but, many have held argument on the what entrepreneurship is. Past scholars have divided entrepreneurship into three principle streams of research namely the consequences, causes and process of entrepreneurship. From these three streams of research, many researchers race to define what entrepreneurship is. Among the many scholars, Bird (1988) describes entrepreneurship as "the pursuit of opportunity beyond the tangible resources that you currently control." From the explanation, no doubt, entrepreneurship emphasize on how opportunity can be identified, committed and control over the resources.

Because of commercial entrepreneurship become mature in the field, SE receives a great call and growing concern from local and international parties (i.e., policies makers, academicians, practitioners) due to its significant in the social and economic transformation of a country (Barton, Schaefer, \& Canavati, 2018; Hockerts, 2017). Tran (2017) reported SE is a dynamically growing phenomenon, but understanding the concept remains limited and have not been adequately explored. Moreover, a lack of consensus remains as to what precisely defines social entrepreneurship (Barton, Schaefer, \& Canavati, 2018). There are two conflicting paradigms in defining SE namely; school of social enterprise and school of social innovation (Ayob, Yap, Amat Sapuan, \& Abdul Rashid, 2013; Krueger, Reilly, $\&$ Carsrud, 2000). The school of social enterprise mentioned $\mathrm{SE}$ is an organization generates income to support their social missions. Whereas, the school of social innovation was concerned with applying innovation how social problems addressed. Therefore, we can describe SE as "enterprising social innovation" or "carrying out innovations that blend methods from the world of business" (Barton, Schaefer, \& Canavati, 2018; Wahid, Ayob, \& Wan Hussain, 2018b).

On the other hand, we have simplified the concept of SE, social enterprise and social entrepreneurs for better understanding. SE is a process in which an entrepreneur makes use of entrepreneurial competencies to undertake entrepreneurial activities to cope with social issues. Notably, social entrepreneurs must perform a behavior socially and entrepreneurially in simultaneous manner. Meaning to say, a social entrepreneur should act entrepreneurially by offering and providing products or services that can generate economic and social value whilst, acting socially is referring the decision making that should be considered for social benefit. Notably, in SE, the social mission will always dominate the financial mission due to its function as "explicit and central." Furthermore, the social mission is the most significant criterion classifying SE from different sorts of entities (Tran, 2017; Ernst, 2011).

On the other hand, social enterprise can be described as "any venture creation for social-purposes". For example, creating social enterprise by transferring social value to the needy segment. Some attempt to call social enterprise as "business with primarily social objectives". For instances, 
using business tool to achieve social objectives to combat the socio-economic problems. While some referring social enterprise as a legal entity that directly targets at social edges to realize each social and economic returns (Tran \& von Korflesch, 2016).

Social entrepreneurs are individuals with the big heart, big dream, big mission to create social value by addressing societal challenges. They can be anybody like politicians, teachers, and writers. They are scattered and widespread throughout the world. What unites them is their role as the innovator. They have a brilliant idea to improve people's life. They are also known as a change agent or community hero to serve needy segment. They are carried many values such as mission-driven, providing sustainable solutions to social problems, visionaries and ultimate realists (Ernst, 2011). Social entrepreneurs have a profound impact on society, but their beneficial functions are still poorly understood and less appreciated, although they often exist for many years.

\section{Social Entrepreneurship Intention}

The idea of venture creation is relying on what a person's intentional (Wang, Chang, Yao, \& Liang, 2016). According to Bird (1988), entrepreneurial intention is a "mental orientation that leads a person in the direction of theory and implementation of specific business concepts". In other word, this venture creation is a planned behavior. None of the enterprise owner start-up venture without a proper planning and strategies (Krueger, Reilly, \& Carsrud, 2000). Understanding the entrepreneurship intention in the context of SE is another part to what extend an individual (i.e., student) is belief to set up social enterprise when they graduated. This phenomenon is crucial to be investigated to with different background and traits.

\section{Trait Emotional Intelligence}

Emotional Intelligence (EI) is a set of capabilities regarding the style or manner of how an individual react on their emotions (Andrei, Siegling, Aloe, Baldaro, \& Petrides, 2016). EI had been around and best-known since year 1960s. The actual idea and thoughts of EI become confusing by the varied EI definitions. The famous Aristotle has summarized EI by that "anybody can become angry - that is easy, but to be angry with the right person and to the right degree and at the right time and for the right purpose, and in the right way - that is not within everybody's power and is not easy." Trait EI concerns about self-perceived abilities in dealing emotions. It can be measured through self-reported (i.e., survey questionnaire). It is also investigated individual's personality hierarchies.

\section{E. Subjective Norm}

Subjective norm is described as "perceiving social pressure whether to perform or not to perform the specific behavior" (i.e., social entrepreneurship) (Kautonen, van Gelderen, \& Fink, 2015; Kautonen, van Gelderen, \& Tornikoski, 2013; Ajzen, 1991). Preceding research observed a robust linkage between norm and intention (Ajzen, 1991; Fishbein \& Ajzen, 1975). Even though the link between subjective norms and intentions is an important doctors, lawyers, engineers, consultants, social workers, help the SE educator in designing a module for students

component of the TRA, empirical research has produced somewhat inconclusive results. Whereas certain investigations have found that subjective norms are a considerable but vulnerable predictor of intentions (Kautonen, van Gelderen, \& Fink, 2015; Kautonen, van Gelderen, \& Tornikoski, 2013), others have reported inconsistent results (Sommer \& Haug, 2011). Some researchers have concluded that subjective norms are strongly dependent on context (Hübner \& Kaiser, 2006). For example, subjective norms do not explain intentions in individualistic cultures, the results are mixed and inconclusive in collectivistic cultures, suggesting the need for conducting additional empirical investigations. In the context of entrepreneurship study, subjective norm is referring to perceived acceptance or rejection of an idea from influential people (i.e., reference group, parent, lecturer, and friend) to start an entrepreneurial activity. This explained that the more someone cares about the opinions, the more believe he/she has towards the people.

Many empirical evidences showed that subjective norm is critical predictors of intentions and behavior. These studies revealed that subjective norm has a positive and significant effect on the decision to complete high school, the effects on new technology implementation and information security (Ngoqo \& Flowerday, 2015). In fact, a study by Budiman \& Wijaya (2014) has also disclosed on the function of the subjective norm as the primary factor that can explain the intention-behavior relationship. Although the finding is negative in nature, yet, it is proven subjective norm play vital roles in determining purchase intention. A person with high subjective norm has low intention to purchase a product, whereas, person with low subjective norm have high intention to shop for.

It is also proven that subjective norm influences SE intention among university's student (Politis, Ketikidis, Diamantidis, \& Lazuras, 2016). Students always been influence by someone that close to him/her. Therefore, identification of the surrounding (i.e., reference group, role model) will help to increase the subjective norm. These reference groups could be lecturers, parents, friends, classmates or other relatives. This study tended to measure on how far this reference group can encourage student opinion on to involve or not involve, their idea to involve, their desire to involve, their expectation to involve and the feeling of being under social pressure to involve in SE activities in HLIs.

Role model is one amongst potential influences on entrepreneurial behavior (Kirkwood, 2007). Manifestly, role models could be increase trait EI particularly towards proactive behavior. Research proven that entrepreneurs with extra confident and resilient can effectively deal with negative emotions (Zhao, Seibert, \& Lumpkin, 2010). Considering characteristics of human beings is different, students with a parent who owns an enterprise will benefit the student in gaining extra resources (i.e., knowledge, asset) regarding ventures creation. This will indirectly increase resistance on the potential stressors level. 
Theoretically, students with high trait EI will actively involve in information seeking to minimize potential stressors.

In contrast, students whom no parent owns an enterprise and possess low trait EI needs to be proactive and creative to search out potential stressors and overcome them (Zampetakis, Kafetsios, Bouranta, Dewett, \& Moustakis, 2009). The above discussion suggested that the viewpoint and influence of family, friends and circle of relatives is significantly important (Ibrahim \& Arshad, 2017). Evidently, Altawallbeh, Soon, Thiam, \& alshourah (2015) found 245 instructors from the six (6) universities confirmed subjective norm mediates the relationship between salient belief (i.e., trait EI) and entrepreneurial intention. On the other hand, 326 samples of postgraduate students from IAU of Rasht and Guilan University revealed that trait EI had a positive association with entrepreneurship intentions. Additionally, trait EI and attitudinal construct (i.e., subjective norm) determined about $55 \%$ of variance on entrepreneurship intentions (Farzin et al., 2013). Therefore, we postulate the following hypotheses:

H1. Trait EI positively related to SE intention

H2. Trait EI positively related to subjective norm

H3. Subjective norm mediates the relationship between trait EI and SE intention

\section{METHODOLOGY AND MATERIAL}

\section{A. Population and Sample Procedures}

This study population consisted of final year students from selected higher learning institutions (HLIs) in Malaysia. The respondents were the undergraduate students pursuing diploma or bachelor's degree programmes in HLIs. Traditionally, selecting undergraduate students is considered as a step before entering self-employment (Politis, Ketikidis, Diamantidis, \& Lazuras, 2016) which is the prime purpose why they are used as a subject sample in this research. In a similar vein, past research has also examined SE intention from undergraduate students' perspectives (Ayob, Yap, Amat Sapuan, \& Abdul Rashid, 2013).

A study was conducted among the 480 undergraduate students from public and private HLIs in Malaysia. Surveys were administered through online survey (Google form). Students were randomly selected and asked to willingly contribute in a research project. Data collection took place in February 2018 and lasted for six weeks. The current study employed the probability sampling category. Stratified sampling technique was applied. The choice of the sampling technique is in line with (Wahid, Ayob, \& Wan Hussain, 2018) recommendation. Stratified sampling design refers to sampling plans where the sample is divided into proportions from the original number of populations (Sekaran \& Bougie, 2016). In this study, we have divided the HLIs into two strata, namely; (a) Public HLI and (b) Private HLI. Each stratum represented five (5) Public HLIs and five (5) Private HLIs. The selection was made because these HLIs offered annual SE-related programs or activities (i.e., community venture, volunteer, social enterprise creation). In terms of sample size, there are few guidelines that have been suggested by past researchers. After considering their suggestions, we considered 500 samples.

\section{B. Measurement of Theoretical Construct}

This study employed a survey questionnaire. The survey questionnaire was designed into four (4) sections. The questions in section A covered the background of HLIs students, such as gender, race, HLIs categories and education levels were all collected in this study. While in section $\mathrm{B}$, the questions covered the trait EI which was adapted and improvised from the Trait Emotional Intelligence Questionnaire (TEIQue). The questions in section $\mathrm{C}$, on the other hand, covered subjective norm. In this study, the instrument was adopted and modified from (Ernst, 2011). Thereafter, it was edited to suit the context of this study. The main reference of the instrument development was by Fishbein \& Ajzen (1975) as they are best known as the developer of the TRA which is widely used and applied by many researchers. Lastly, the questions in section D covered SE intention. The items of social entrepreneurship intention were borrowed and improvised from Liñán \& Chen (2009) and Ip, Wu, Liu, \& Liang (2017). The instrument was using a 7-Likert scale ranging from 1 (Completely Disagree) to 7 (Completely Agree) which were used to measure the items.

\section{Analytical Strategy}

In this study, we used two statistical packages for analyzing the data. First, Statistical Package for the Social Sciences (SPSS) software was employed for preliminary analysis (i.e., descriptive statistic). Later, another advance statistical package Analysis Moment of Structures (AMOS) software was used for assisting on the main analysis. Structural Equation Modelling (SEM) is the approach applied to test the hypotheses of the study. The advantage of using SEM is it allows both evaluation of measurement and structural relationships hypothesized; and linkages exists connecting variables. As recommended by Zampetakis, Kafetsios, Bouranta, Dewett, \& Moustakis (2009), this research tested the conceptual model using a two-level analysis technique. The first step, a measurement model was examined, followed by examining the structural model. We additionally employed numerous statistics as proposed by Awang (2015) such as absolute fit, incremental fit and model fit.

\section{RESULT AND FINDINGS}

\section{A. Descriptive Analysis}

Out of 500, only 480 valid questionnaires were returned and analyzed with 96 per cent response rate. Approximately, seventy-two per cent of the students are female, similar to that of the student population in Malaysian universities. As for the race segment, majority of respondents were Malays (56.9 per cent), followed closely by Chinese students (20 per cent). Indian and other races contributed about 12.7 per cent and 10.4 per cent respectively. Majority of the samples were from public institutions of 66 per cent. Of 480 respondents 311 were pursuing bachelor's degree program while 169 sample studying diploma level. Referring to Table 1 , it is 
displaying percentages means and standard deviations of sample characteristics

Table 1. Sample Characteristics

\begin{tabular}{cccccc}
\hline Variables & Items & F & $\%$ & Mean & Std. Dev \\
\hline Gender & Male & 130 & 27.1 & 1.58 & 0.498 \\
& Female & 350 & 72.9 & & \\
\hline Race & Malay & 276 & 56.9 & 1.77 & 1.030 \\
& Chinese & 96 & 20.0 & & \\
& Indian & 61 & 12.7 & & \\
& Others & 50 & 10.4 & & \\
\hline $\begin{array}{c}\text { HLIs } \\
\text { category }\end{array}$ & Public HLIs & 317 & 66.0 & 1.34 & 0.474 \\
& Private HLIs & 163 & 34.0 & & \\
\hline $\begin{array}{c}\text { Education } \\
\text { level }\end{array}$ & Diploma & 169 & 35.2 & 1.61 & 0.489 \\
& Degree & 311 & 64.8 & &
\end{tabular}

Notes: $\mathrm{N}=480 ; \mathrm{F}=\mathrm{Frequency}, \%=$ Percentage, $\mathrm{HLI} \mathrm{s}=$ Higher LearningInstitutions, Std. Dev= StandardDeviation

\section{B. Measurement Model}

In this model, we revealed the model fitness and average variance extracted (AVE). The AVE offers calculation on the variance of construct in relation to the variance of measurement error (Fornell \& Larcker, 1981). Therefore, the latent construct highly reliable when the value of AVE is exceeding the threshold of 0.50 . In this study, we reported the AVE for each factor was as follows: 0.691 for trait EI, 0.776 for SE intent, and 0.683 for subjective norm. These indicated that the latent variables had achieved excellent reliabilities result. On the other hand, as presented in Table 2 , the measurement model fit is considerably accepted as the index indicator evaluated (Awang, 2015).

Table 2. Measurement Model Fitness

\begin{tabular}{lcccc}
\hline & \multicolumn{2}{c}{ Absolute Fit } & \multicolumn{2}{c}{ Incremental Fit } \\
\hline Model & RMSEA & GFI & TLI & CFI \\
\hline Model 1 & 0.68 & 0.901 & 0.892 & 0.900 \\
Notes: n=480; RMSEA=Root & Mean Square Error; & Rer \\
GFI=Goodness of Fit Index; TLI= Tucker-Lewis Index; \\
CFI= ComparativeFit Index; $d$; $\mathrm{p}<0.001$.
\end{tabular}

\section{Structural Model}

We tested three models as in line to our study hypotheses. The first model tests the relationship between the trait EI and SE intention (H1). It is reported insignificant relationship between these variables $(\beta=0.07, p=0.268)$. This result is obviously contradicted to prior researches. Therefore, the $\mathrm{H} 1$ is rejected. The second model tested the effect of trait EI on subjective norm (H2) showed a positively significant relationship $(\beta=0.610, p=0.000)$. This result is likely better than previous SE intention studies (Tiwari, Bhat, \& Tikoria, 2018). The third model tested the indirect effect of trait EI, subjective norm on SE intent. At this level, the $(\mathrm{H} 3)$ showed a positive relationship $(\beta=$ $0.390, \mathrm{p}=0.000)$. Therefore, subjective norm is partially mediate the relationship between trait EI and SE intention.

\section{DISCUSSION}

Today, limited researches that investigate factors particularly associated to individual emotionally intelligence trait (Tiwari , Bhat, \& Tikoria, 2017; Tiwari, Bhat, \& Tikoria, 2018; Othman \& Tengku Muda, 2018). To our knowledge, this current study is among the earliest attempt to explore the relationships between trait EI, subjective norm within the context of SE. The ultimate interest in this research is the development of future social entrepreneurs among HLIs students. At this point, we tried to empirically verify the relationship between trait EI and subjective norm to formulate better SE intention modelling in Malaysia context.

Theoretically, this research is addressing the model that adheres to TRA. The findings revealed that trait EI is an essential antecedent to subjective norm. Surprisingly, trait EI is not the predictor to SE intention. What interesting of this current research is the contradictory result from previous scholars that has led to further investigation (Creswell, 2014). Conversely, trait EI is found insignificant to SE intention. Although, scholars like Tiwari, Bhat, \& Tikoria, (2018) and Zampetakis, Kafetsios, Bouranta, Dewett, \& Moustakis (2009) propagate the significant linkage between trait EI and SE intention, yet, the role of trait EI in this study remain controversial. According to Andrei, Siegling, Aloe, Baldaro, \& Petrides (2016), trait EI concerns the nature of emotional experience. But, in this study the students were: (1) unable to cope with emotion effectively (2) lack of experience working with the community or any non-profit organization entity. Some attempt to blame the institution (i.e., university) because the social activities is a compulsory to perform. Another part, they did it for the mark and they have no emotional desirability involved.

On the other hand, trait EI positively related to subjective norm. As the result revealed, the opinion and influence of colleagues and own family is of mammoth importance in many countries (Ibrahim \& Arshad, 2017) and proposed that subjective norm will substantially impact on student's intention. Students with high trait EI might be vigorously involved in information seeking to minimize potential stressors. Meanwhile, students with low trait EI needs to have both proactive and creative to locate capability stressors and triumph over them (Zampetakis, Kafetsios, Bouranta, Dewett, \& Moustakis, 2009).

This paper has some limitations. First, the approach used to evaluate the studied variables was self-report, therefore the issue of common method variance (CMV) is occurred. As most scholars suggested, longitudinal research is critically needed to solve the problem. As mentioned by Zampetakis, Kafetsios, Bouranta, Dewett, \& Moustakis (2009), they cannot be sure the path correlation of trait EI, entrepreneurial attitudes and intention is being accessed precisely through survey assessment. Yet, the result of this present paper is expected to contribute to both theoretical and methodological. Theoretically, our team has contributed to the developing body of literature on SE intentions. In term of methodological, this paper presented students as sample from both public and private HLIs. This research can be proven beneficial globally where $\mathrm{SE}$ is a rising phenomenon in tremendous pace, however research on this discipline continues to be struggling to pave their path. 
Second, in dealing with emotion is not an easy task. Designing the research solely from quantitative viewpoint giving a gap especially in understanding the respondents. As Othman \& Tengku Muda (2018) recommended that qualitative research methods should be executed. Qualitative analysis will facilitate researchers to access the thoughts and feelings of respondents allow to apprehend student's experiences and face expression. Alternatively, quantitative analysis is often accustomed to verifying the degree to which students undertake certain behaviors. Thus, a combination of quantitative and qualitative analyses is probably going to portray better findings associated with EI and SE intention among students.

\section{CONCLUSION}

In conclusion, educating student with SE would be pertinent to younger generations in any country. Acknowledging SE as a part of entrepreneurship, it can an effective aid to minimise unemployment and increase job opportunities and career development programmes. In this paper, the students surveyed generally responded accordingly toward the constructs under investigation. We believe nurturing the SE at every faculties would benefit many stakeholders included Ministry of Higher Education, social enterprise, educators, policy makers and researchers. The study also found that, the students who were exposed in SE activities would most likely have greater intention in becoming social entrepreneurs. Consequently, it turned into very useful if the authorities can be designing programmes that inspire students to engage in SE.

\section{ACKNOWLEDGEMENT}

The authors would like to extend their gratitude to the anonymous reviewer(s) and the team hard work.

\section{REFERENCES}

1. Ab Wahid, H., Wan Mustaffa, W., Mohd Rhouse, S., \& Abdul Rahman, R. (2016). Social entrepreneurship and resilience among public university students in Malaysia. International Journal of Academic Research in Business and Social Sciences, 6(12), 171-184.

2. Ajzen, I. (1991). The theory of planned behavior. Organizational Behavior and Human Decision Process, 50(1), 179-211.

3. Altawallbeh, M., Soon, F., Thiam, W., \& alshourah, S. (2015). Mediating role of attitude, subjective norm and perceived behavioural control in the relationship between their respective salient beliefs and behavioral intention to adopt e-learning among instructors in Jordanian universities. Journal of Education and Practice, 6(11), 152-159.

4. Andrei, F., Siegling, A. B., Aloe, A. M., Baldaro, B., \& Petrides, K. V. (2016). The incremental validity of the trait emotional intelligence questionnaire (TEIQue): A systematic review and meta-analysis. Journal of Personality Assessment, 98(1), 261-276.

5. Awang, Z. (2015). SEM made simple: A gentle approach to learning structural equation modeling. Malaysia: MPWS Rich Publication.

6. Ayob, A. H. (2017). Diversity, trust and social entrepreneurship. Journal of Social Entrepreneurship, 9(1), 1-17.
7. Ayob, N., Yap, C. S., Amat Sapuan, D., \& Abdul Rashid, M. (2013). Social entrepeneurship intention among business undergraduate: An emerging economy perspective. Gadjah Mada International Journal of Business, 15(3), 249-267.

8. Barton, M., Schaefer, R., \& Canavati, S. (2018). To be or not to be a social entrepreneur: Motivational drivers amongst American business students. Entrepreneurial Business and Economics Review, 6(1), 6-35.

9. Bird, B. (1988). Implementating entrepreneurial idea: The case of intention. Academy of Management Review, 13(3), 442-453

10. Budiman, S., \& Wijaya, T. (2014). Purchase intention of counterfeit products: The role of subjective norm. International Journal of Marketing Studies, 6(2), 145152

11. Creswell, J. W. (2014). Research Design. Qualitative, Quantitative and Moxed Method Approaches. 4th edition. USA: SAGE Publication.

12. Ernst, K. (2011). Heart over mind - An empirical analysis of social entrepreneurship intention formation on the basis of the theory of planned behavior. Berlin: Univeristy of Wuppertal.

13. Farzin , F., Azadehdel, M., Mofidi, M. k., Shahabi, S., khoshamooz, H., Pazhouh, L. D., . . . Shadkam, F. (2013). The relationship between trait emotional intelligence and entrepreneurship attitudes and intentions. Journal of Public Administration and Policy Research, 6(11), 79-85.

14. Fishbein, M., \& Ajzen, I. (1975). Belief, attitude, intention and behavior: An introduction to theory and research. Phillipines: Addison-Wesley Publishing Company.

15. Fornell , C., \& Larcker, D. F. (1981). Evaluating structural equation models with unobservable variables and measurement error. Journal of Marketing Research, 18(2), 39-50.

16. Hassan, R. A., \& Omar, S. (2016). The effect of emotional intelligence and entrepreneurial attitude on entrepreneurial intention. Arabian Journal of Business and Management Review, 5(12), 1-10.

17. Hockerts, K. (2017). Determinants of social entrepreneurial intentions. Entrepreneurship Theory \& Practices, 105-130.

18. Hübner, G., \& Kaiser, F. G. (2006). The moderating role of the attitude-subjective norms conflict on the link between moral norms and intention. European Psychologist, 11(1), 99-109.

19. Ibrahim, Y., \& Arshad, I. (2017). Examining the impact of product involvement, subjective norm, and perceived behavioral control on investment intentions of individual investors in Pakistan. Investment Management and Financial Innovations, 14(4), 181-193.

20. Ip, C. Y., Wu, S.-C., Liu, H.-C., \& Liang, C. (2017) Social entrepreneurial intention of students from Hong Kong. Journal of Entrepreneurship, 27(1), 47-64.

21. Kautonen, T., van Gelderen, M., \& Fink, M. (2015). Robustness of the theory of planned behavior in predicting entrepreneurial intention and actions. Entrepreneurship Theory \& Practices, 39(3), 655-674.

22. Kautonen, T., van Gelderen, M., \& Tornikoski, E. T. (2013). Predicting entrepreneurial behaviour: A test of the theory of planned behavior. Applied Economics, 45(6), 697-707 
23. Kedmenec, I., Rebernik, M., \& Perip, J. (2015). The impact og individual characteristics on intentions to pursue social entrepreneurship. EKONOMSKI PREGLED, 66(2), 119-137.

24. Kirkwood, J. (2007). Igniting the entrepreneurial spirit: Is the role of parents play gendered? International Journal of Entrepreneurial Behavior \& Research, 13(1), 39-59.

25. Krueger, N. F., Reilly, M. D., \& Carsrud, A. L. (2000). Competing model of entrepreneurial intentions. Journal of Business Venturing, 15(5/6), 411- 432.

26. Liñán, F., \& Chen, Y.-W. (2009). Development and cross-cultural application of a specific intrument to measure entrepreneurial intentions. Entrepreneurship Practices \& Theory, 593-617.

27. Ngoqo, B., \& Flowerday, S. (2015). Exploring the relationship between students mobile information security awareness and behavioral intent. Information and Computer Security, 23(4), 406-420.

28. Othman, N., \& Tengku Muda, T. (2018). Emotional intelligence towards entrepreneurial career choice behaviors. Education + Training, 60(9), 953-970.

29. Politis, K., Ketikidis, P., Diamantidis, A. D., \& Lazuras, L. (2016). An investigation of social entrepreneurial intention formation among South-East European postgraduate students. Journal of Small Business and Enterprise Development, 23(4), 1120-1141.

30. Sekaran, U., \& Bougie, R. (2016). Research methods for business: A skill building approach. 7th edition. Singapore: John WIley \& Sons (Asia).

31. Shepherd, D. A., Patzelt, H., \& Wolfe, M. (2012). Moving forward from project failure: Negative emotions, affective commitment and learning from experience. Academy of Management Journal, 54(6), 1229-1259.

32. Shepherd, D. A., Wiklund, J., \& Haynie, M. J. (2009). Moving forward: Balancing the financial and emotional costs of business failure. Journal of Business Venturing, 24(2), 134-148.

33. Sommer, L., \& Haug, M. (2011). What influences implementation intentions in an academic learning context- the roles of goal intentions, procrastination and experience. International Journal of Higher Education, $1(1), 32-61$.

34. Tiwari, P., Bhat, A. K., \& Tikoria, J. (2017). The role of emotional intelligence and self-efficacy on social entrepreneurial attitudes and social entrepreneurship intentions. Journal of Social Entrepreneurship, 1-20.

35. Tiwari, P., Bhat, A. K., \& Tikoria, J. (2018). Factors affecting individual's intention to become a social enterpreneur. In A. Agrawal, \& P. Kumar, Social entrepreneurship and sustainable business models: The case of India (pp. 59-98). Switzerland: Palgrave Macmilan, Springer International Publishing.

36. Tran, A. T. (2017). Factors influencing social entrepreneurship intention: A theoretical model. 89th ISERD International Conference (pp. 17-38). Oxford: United Kingdom.

37. Tran, A. T., \& von Korflesch, H. (2016). A conceptual model of social entrepreneurship intention based on social cognitive career theory. Asia Pacific Journal of Innovation and Entrepreneurship, 10(1), 17-38.

38. Wahid, S. M., Ayob, A. H., \& Wan Hussain, W. (2018a). The formation of community heroes in Malaysia: An extended theory of planned behavior. International Journal of Business and Management Science, 8(2), 495509 .

39. Wahid, S. M., Wan Hussain, W., \& Ayob, A. H. (2018b). The growing trend of social entrepreneurship among Malaysian Undergraduate Students. International Journal of Academic Research in Business and Social Sciences, 8(9), 1034-1046.

40. Walsh, G. S., \& Cunningham, J. A. (2016). Business failure and entrepreneurship: Emergence, evolution and future research. Foundations and Trends in Entrepreneurship, 12(3), 163-285.

41. Wan Hussain, W., Ab Rahman, M., Zainol, Z., \& Yaakub, N. (2014). Mechanism and government initiatives promoting innovation and commercialization of university invention. Pertanika Journal of Social Science \& Humanity, 22(S), 131-148.

42. Wang, J. H., Chang, C.-C., Yao, S. N., \& Liang, C. (2016). The contribution of self-efficacy to the relationship between personality traits and entrepreneurship intention. Higher Education, 72(2), 209-224.

43. Zampetakis, L. A., Kafetsios, K., Bouranta, N., Dewett, T., \& Moustakis, V. S. (2009). On the relationship between emotional intelligence and entrepreneurial attitudes and intentions. International Journal of Entrepreneurial Behavior \& Research, 15(6), 595-618.

44. Zhao, H., Seibert, S. E., \& Lumpkin, G. (2010). The relationship of personality to entrepreneurial intentions and performance: A meta-analytic review. Journal of Management, 36, 381-404.

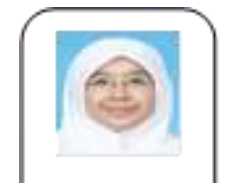

\section{AUTHORS PROFILE}

Siti Daleela Mohd Wahid is a doctorate studen at the National University of Malaysia. She received a master's degree in Entrepreneurship from Universiti Teknologi MARA, Malaysia. Currently, her interest is focuses on the current state of social entrepreneurship and development of

social enterprise.

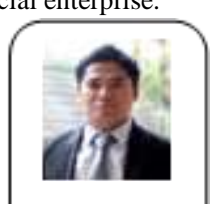

Abu Hanifah Ayob is an assistant professor at the Faculty of Economics and Management, the National University of Malaysia, recently completed his post doctorate at Copenhagen Business School and Toulouse Business School. He earned MSc. in Management from Toulouse Business School and $\mathrm{PhD}$ in Management Science from Universite Toulouse 1 Capitole. His current research interest focuses on the exploration of social context for non-profit organizations

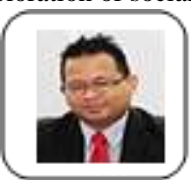

Wan Mohd Hirwani Wan Hussain is an assistant professor at the Graduate School of Business, the National University of Malaysia. He earned master's degree and $\mathrm{PhD}$ from the National University of Malaysia. He is specializing in technology transfer, innovation technology, internet marketing and commercialization university research. His current research interest is on entrepreneurial strategy, social enterprise and social innovation. 